\title{
Tin Whisker Growth Induced by High Electron Current Density
}

\author{
Y.W. LIN,${ }^{1}$ YI-SHAO LAI,${ }^{2}$ Y.L. $L I N,{ }^{3}$ CHUN-TE TU, ${ }^{4}$ and C.R. $\mathrm{KAO}^{1,5}$ \\ 1.-Department of Materials Science and Engineering, National Taiwan University, Taipei, \\ Taiwan. 2.-Advanced Semiconductor Engineering, Inc., Kaohsiung, Taiwan. 3.-Department of \\ Chemical \& Materials Engineering, National Central University, Jhongli, Taiwan. 4.-Henkel \\ Accurus Scientific Co., Ltd., Tainan, Taiwan. 5.-e-mail: crkao@ntu.edu.tw
}

\begin{abstract}
The effect of electric current on the tin whisker growth on Sn stripes was studied. The Sn stripes, $1 \mu \mathrm{m}$ in thickness, were patterned on silicon wafers. The design of the Sn stripes allowed the simultaneous study of the effect of current crowding and current density. Current stressing was performed in ovens set at 30,50 , or $70^{\circ} \mathrm{C}$, and the current density used ranged from $4.5 \times 10^{4} \mathrm{~A} / \mathrm{cm}^{2}$ to $3.6 \times 10^{5} \mathrm{~A} / \mathrm{cm}^{2}$. It was found that the stress induced by the electric current caused the formation of many Sn whiskers. A higher current density caused more Sn whiskers to form. Of the three temperatures studied, $50^{\circ} \mathrm{C}$ was the most favorable one for the formation of the Sn whiskers. In addition, the current-crowding effect also influenced whisker growth.
\end{abstract}

Key words: Tin whisker, electromigration, current crowding

\section{INTRODUCTION}

The Sn surface finish is a very promising lead-free replacement for the eutectic PbSn surface finish for electronic components. Nevertheless, one key concern about the Sn surface finish is the tendency for the spontaneous growth of tin whiskers. ${ }^{1,2}$ Tin whisker growth is a well-known stress relief phenomenon. Excessive growth of long whiskers presents the possibility that two neighboring circuits might be bridged, causing short circuit failure. The first published report of tin whiskers dates back to the $1940 \mathrm{~s}^{3}$ Since then, many researchers have studied the factors affecting whisker formation. ${ }^{4-12}$ It is generally accepted that the coupling of two irreversible processes is necessary for tin whisker growth. ${ }^{12}$ First, a continuous compressive stress must be generated in the Sn to maintain the driving force. Second, the continuous stress generation in $\mathrm{Sn}$ is relaxed through the growth of whiskers to maintain dynamic equilibrium. ${ }^{12}$ Any process that can generate compressive stress may contribute to the growth of the Sn whiskers. To date, sources of compressive stress originating from mechanical, thermal, and chemical processes have been identified.

(Received March 15, 2007; accepted July 23, 2007;

published online September 11, 2007)
It is widely known that electromigration can generate back-stress in metal lines. When an electric current passes through a metal line with a finite length, the atoms in the metal line are pushed by the moving electrons in the direction of the electron flow. The electromigration of the metal atoms builds up a compressive stress field on the anode side. This led to the possibility that electric current might also contribute to the formation of the Sn whiskers. Recently, it was indeed observed that electron flow could cause Sn whisker growth in straight $\mathrm{Sn}$ lines. ${ }^{13}$ It was reported that the whisker growth rate was faster when the applied current density was higher. ${ }^{13}$ However, the geometry of the Sn stripes used was limited to straight lines,${ }^{13}$, and the effect of current crowding was not investigated. One of the objectives of this study is to use Sn stripes of a more complicated geometry so that the effect of current crowding can be studied.

\section{EXPERIMENT}

The Sn line pattern used in this study is shown in Fig. 1. The circles are the contact pads for the electrodes. Any two of the five pads could serve as the electron input or output terminals so that electrons could pass through the desired segment(s) of the pattern. The width of the segments ranged from 


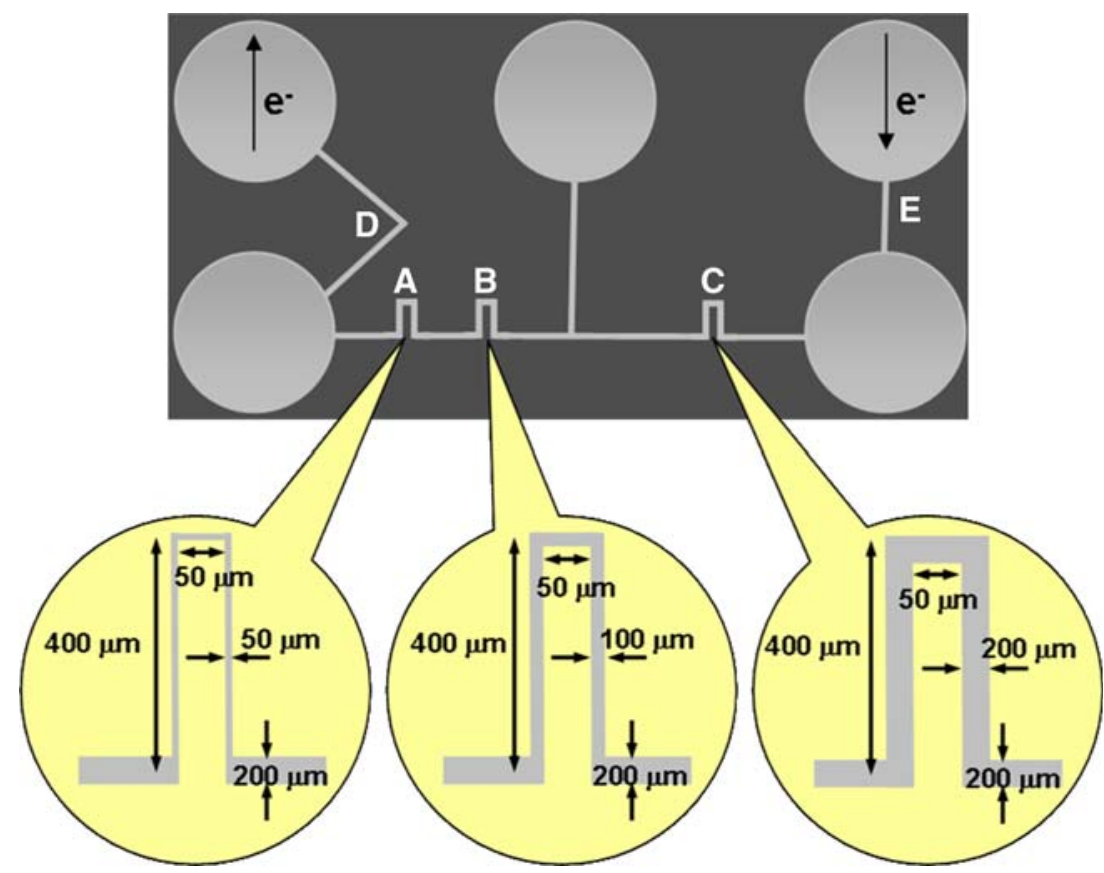

Fig. 1. Tin stripe pattern used in this study. The circles are the contact pads for the electrodes. The thickness of the $\mathrm{Sn}$ pattern is $1 \mu \mathrm{m}$.

$50 \mu \mathrm{m}$ to $200 \mu \mathrm{m}$, depending on the location. The thickness of the Sn pattern was $1 \mu \mathrm{m}$. The substrates were p-type silicon wafers.

The Sn line pattern was formed by homogeneously sputtering a layer of copper film over the substrate first. A standard lithography process was then used to define the $\mathrm{Cu}$ stripe pattern, whose dimensions are shown in Fig. 1. Afterward, the $\mathrm{Cu}$ pattern was replaced by the Sn pattern through a typical Sn immersion process, which is an electroless deposition technique often used by the printed circuit board industry to grow the Sn surface finish over $\mathrm{Cu}$ conducting traces. The resulting Sn pattern had exactly the same dimensions as those of the $\mathrm{Cu}$ pattern that it replaced. The thickness of the tin stripe was controlled at $1 \mu \mathrm{m}$.

The direction of the electron flow during the electromigration tests is shown in Fig. 1. The applied currents were $0.1 \mathrm{~A}$ or $0.2 \mathrm{~A}$ in this study. The tests were performed inside ovens set at 30,50, or $70^{\circ} \mathrm{C}$. The test parameters are summarized in Table I. The number of tin whiskers was determined by scanning electron microscopy (SEM).

\section{RESULTS AND DISCUSSION}

\section{Current Density Effect}

Sample sets 1 and 3 underwent the same test parameters except the applied current. A comparison of the results from these two sets of experiment revealed the effect of the current density. The results from sample set 1 are presented first. Figure $2 \mathrm{a}-\mathrm{d}$ shows the Sn stripes at location A after 1, 5,10 , and $12 \mathrm{~h}$ of current stress, respectively. It should be pointed out that the micrographs in Fig. 2 are from different specimens. The specimens in

Table I. Test Parameters Used in this Study

\begin{tabular}{|c|c|c|c|c|c|c|c|}
\hline \multirow[b]{2}{*}{$\begin{array}{l}\text { Sample } \\
\text { Set }\end{array}$} & \multirow[b]{2}{*}{$\begin{array}{c}\text { Applied } \\
\text { Current (A) }\end{array}$} & \multirow[b]{2}{*}{$\begin{array}{c}\text { Oven } \\
\text { Temperature }\left({ }^{\circ} \mathrm{C}\right)\end{array}$} & \multicolumn{5}{|c|}{ Current Density $\left(10^{5} \mathrm{~A} / \mathrm{cm}^{2}\right)$} \\
\hline & & & Location A & Location B & Location C & Location D & Location $\mathbf{E}$ \\
\hline 1 & 0.2 & 50 & 3.6 & 1.8 & 0.9 & 0.9 & 0.9 \\
\hline 2 & 0.1 & 30 & 1.8 & 0.9 & 0.45 & 0.45 & 0.45 \\
\hline 3 & 0.1 & 50 & 1.8 & 0.9 & 0.45 & 0.45 & 0.45 \\
\hline 4 & 0.1 & 70 & 1.8 & 0.9 & 0.45 & 0.45 & 0.45 \\
\hline 5 & 0.0 & $30,50,70$ & 0.0 & 0.0 & 0.0 & 0.0 & 0.0 \\
\hline
\end{tabular}

Sample set no. 5 was a control experiment, composed of three specimens that were kept in the ovens at 30,50 , and $70^{\circ} \mathrm{C}$, respectively, without any current being applied. 

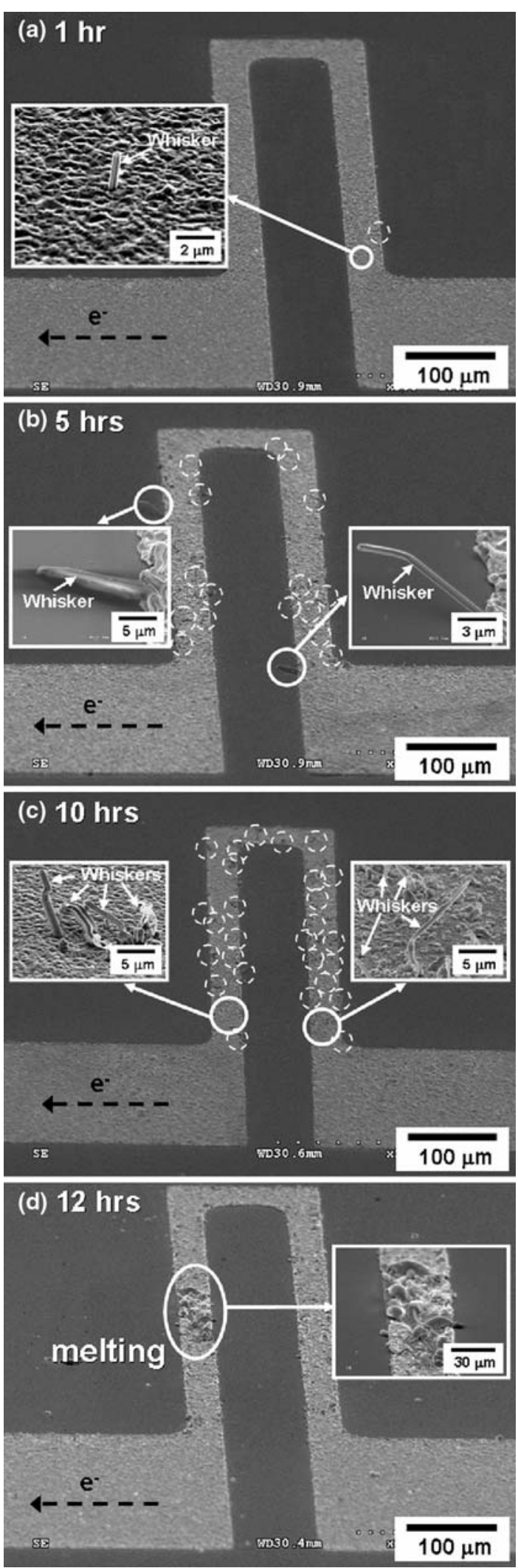

Fig. 2. SEM images at location $A$ of sample set 1 after (a) $1 \mathrm{~h}$, (b) $5 \mathrm{~h}$, (c) $10 \mathrm{~h}$, and (d) $12 \mathrm{~h}$ of current stress.
Fig. 2a were stressed continuously for $1 \mathrm{~h}$, and were then examined under SEM. The specimen in Fig. $2 \mathrm{~b}$ was a different specimen and was stressed continuously for $5 \mathrm{~h}$ without interruption. All the other specimens in this study were handled this way. We did try to use one specimen for multiple stressingSEM cycles. In other words, we tried to apply the current stress again to the same specimen after the SEM observation so that we could follow the growth of each individual Sn whisker. Unfortunately, during SEM observation, the accumulated internal stress in the Sn stripes was relieved due to the e-beam irradiation. The e-beam irradiated Sn stripes had to go through an incubation period for the stress to accumulate before the whisker would grow again. As a result, the extent of the Sn whisker growth from a specimen that goes through two 2-h stress-SEM cycles will be different from that of a specimen that goes through a continuous 4 -h stressing.

Figure 2a shows that after $1 \mathrm{~h}$ of current stress, a few whiskers had formed at region $A$. At regions B-E, where the current density was lower, no whiskers could be observed. Figure $2 b$ and $c$ shows that many more whiskers had formed and that these whiskers tended to grow longer with time. There were only a few isolated whiskers in region $\mathrm{B}$ and no whisker at all in regions $\mathrm{C}-\mathrm{E}$ after $10 \mathrm{~h}$ of current stress.

It should be noted that no whisker at all was observed in sample set 5 . In other words, when there was no applied current, no whiskers would grow. Therefore, it can be concluded that the growth of tin whisker in this study was driven by electric current alone.

After $12 \mathrm{~h}$ of stress, an open circuit formed due to local melting of the Sn stripe, as shown in Fig. 2d. With the growth of the whiskers, Sn atoms were driven away from a certain region, causing the local cross-sectional area of the Sn stripe to decrease. The decrease in the local cross-sectional area increased the local current density, driving more Sn atoms away. This vicious cycle continued until the Sn stripes could not carry such a high local current density and it melted locally.

When the current applied was reduced to $0.1 \mathrm{~A}$ (sample set 3), a few whiskers were observed only after $10 \mathrm{~h}$ of stressing, as shown in Fig. 3a. As before, longer aging increased the number, as well as the length, of the whiskers, as shown in Fig. 3b. In summary, at $50^{\circ} \mathrm{C}$ environmental temperature, the incubation time for the whicker growth increased from about $1 \mathrm{~h}$ to $10 \mathrm{~h}$ when the current density was decreased from $3.6 \times 10^{5} \mathrm{~A} / \mathrm{cm}^{2}$ to $1.8 \times 10^{5} \mathrm{~A} / \mathrm{cm}^{2}$.

\section{Temperature Effect}

Sample sets 2, 3, and 4 underwent the same test parameters except the oven temperature. A comparison of the results from these three sets of 

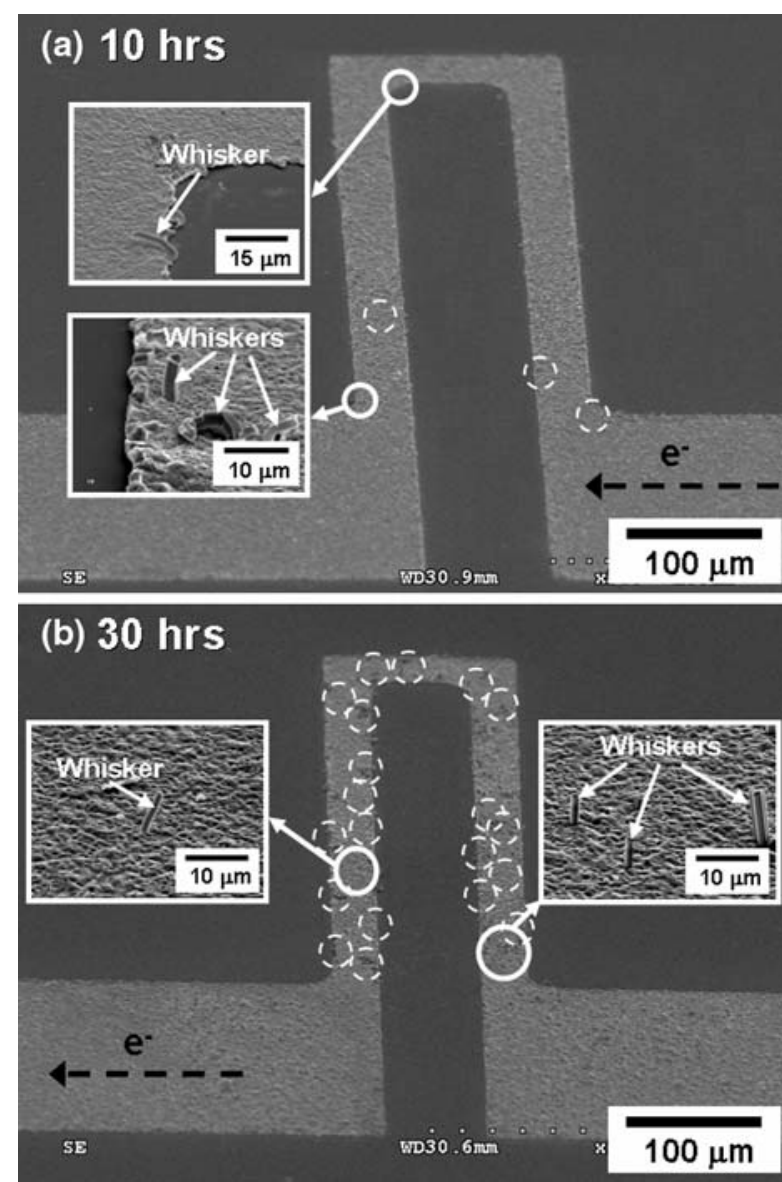

Fig. 3. SEM images at location A of sample set 3 after (a) $10 \mathrm{~h}$, and (b) $30 \mathrm{~h}$ of current stress.

experiments reveals the effect of the temperature. Figure 4 shows the whisker growth at $30^{\circ} \mathrm{C}$ (sample set 2). A comparison between Figs. 3 and 4 shows that the numbers of whiskers at $50^{\circ} \mathrm{C}$ were slightly more than those at $30^{\circ} \mathrm{C}$. The rise in the temperature from $30^{\circ} \mathrm{C}$ to $50^{\circ} \mathrm{C}$ accelerated the electromigration, because electromigration, in itself, is a diffusion process. More electromigration raised the compressive stress, and, as a result, the numbers of tin whiskers increased.

Nevertheless, accelerated electromigration was not the only effect caused by the temperature increase; temperature increase, in fact, also accelerated the relief of the internal stress. It should be noted that whisker growth is only one of the stress relief mechanisms. There are other stress relief mechanisms, such as grain rotation and plastic deformation, that can also be accelerated by increased temperature. One of those mechanisms might even have become the dominant stress relief mechanism, so that whisker growth was no longer important. This was, indeed, what we observed when the temperature was increased to $70^{\circ} \mathrm{C}$. As shown in Fig. 5a, no obvious whisker growth was observed on the tin stripe after $30 \mathrm{~h}$ of current stress. We did, however, observe the formation of
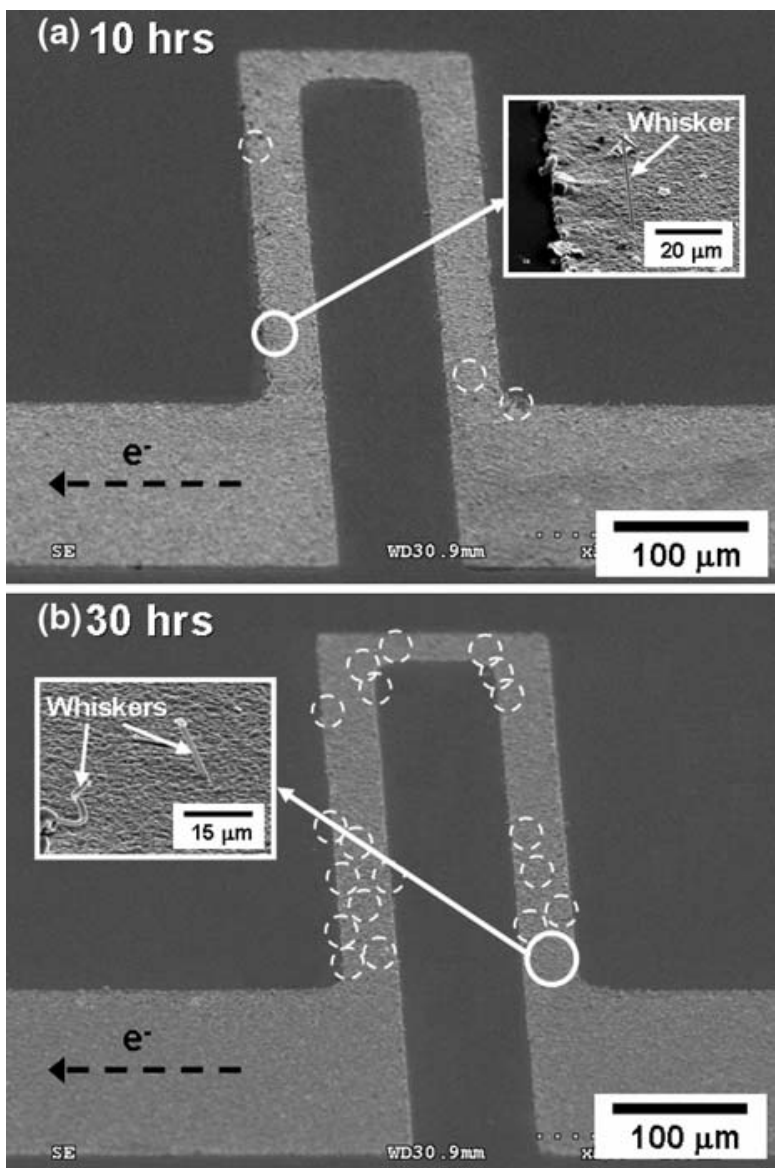

Fig. 4. SEM images at location $A$ of sample set 2 after (a) $10 \mathrm{~h}$, and (b) $30 \mathrm{~h}$ of current stress.

hillocks, as displayed in Fig. 5b. Apparently, stress relaxation through the hillock formation was the dominant mechanism. The fact that tin and tin oxide became softer at $70^{\circ} \mathrm{C}$ might have been a key factor contributing to the formation of hillocks instead of whiskers. As the tin oxide became softer with increasing temperature, the pinholes through which the whiskers grew became less strong, and the pinholes were consequently made larger by the extruding Sn whiskers. The net result was that the diameter of the tin whiskers became larger, and, eventually, the diameter became so large that the whiskers became hillocks. It should be pointed out that hillock formation is not as dangerous as whisker formation, because hillocks are much shorter and less likely to cause short circuit failure.

From the results presented here, it is logical to speculate that there is an optimum temperature for whisker growth. This temperature is likely to be between $30^{\circ} \mathrm{C}$ and $70^{\circ} \mathrm{C}$. Nevertheless, additional study is needed to establish this assumption.

\section{Current-Crowding Effect}

The evidence for the current-crowding effect did not appear until the stressing time had reached $50 \mathrm{~h}$ at location $\mathrm{C}$ of sample set 1 , as shown in 

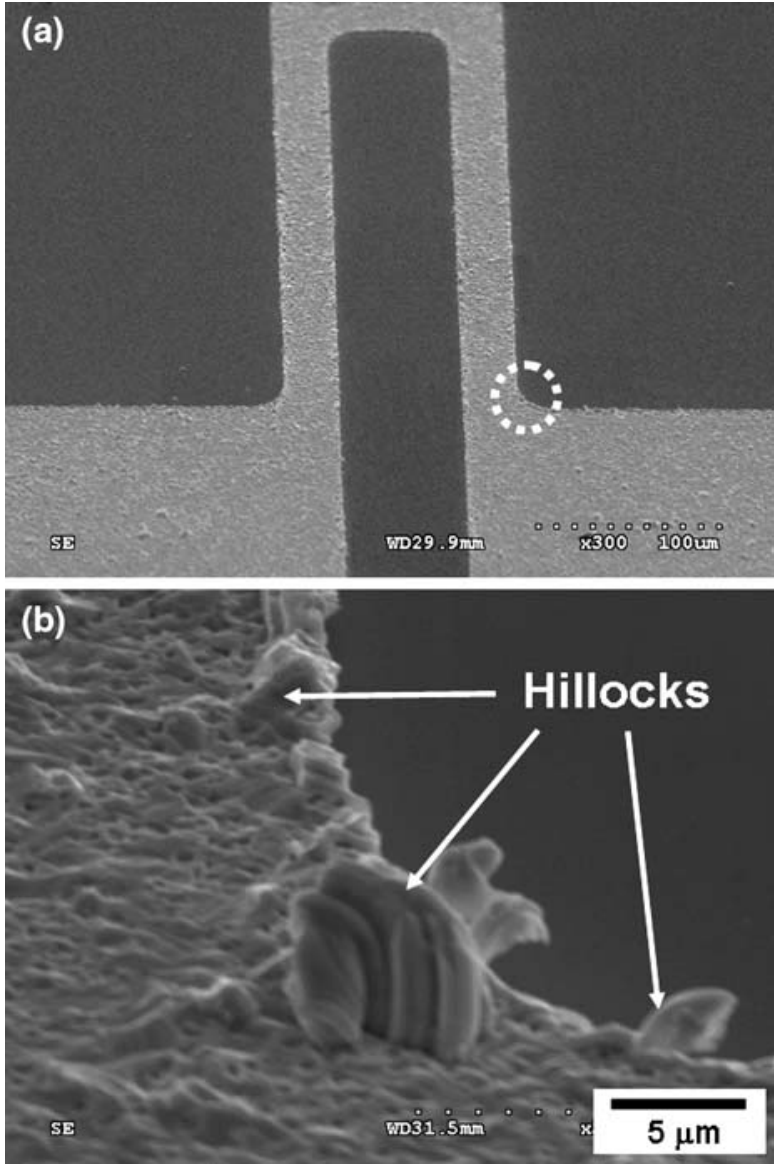

Fig. 5. (a) SEM images at location A of sample set 4 after $30 \mathrm{~h}$ of current stress. (b) Zoom-in micrograph of the circle in (a). The growth of the whiskers was replaced by the growth of the hillocks.

Fig. 6a. During the acquisition of the results shown in Fig. 6, the locations A and B had been by-passed. In other words, the electron current left the $\mathrm{Sn}$ stripe through the contact pad between location B and location $\mathrm{C}$ shown in Fig. 1. If locations A and B had not been by-passed, the Sn stripe would have failed at location $\mathrm{A}$ after about $12 \mathrm{~h}$ of current stress. It can be clearly seen that whiskers only appeared at the inner corners of the $90^{\circ}$ turn between the two connecting line segments. There was no whisker at the outer corners of the $90^{\circ}$ turn. The number of whiskers at the inner corner increased with the stress time, as shown in Fig. 6b and c. It should be pointed out that the inner corners were where the current-crowding effect was important. A finite element simulation of the current density distribution for location $\mathrm{C}$ is shown in Fig. 7. The simulation shows that the inner corners, indeed, have the highest current density and the highest current density gradient.

The average current density at location $\mathrm{C}$ of sample set 1 was, in fact, relatively low: only onequarter of that at location A. As shown in Fig. 2a, it took only $1 \mathrm{~h}$ for some whiskers to form at
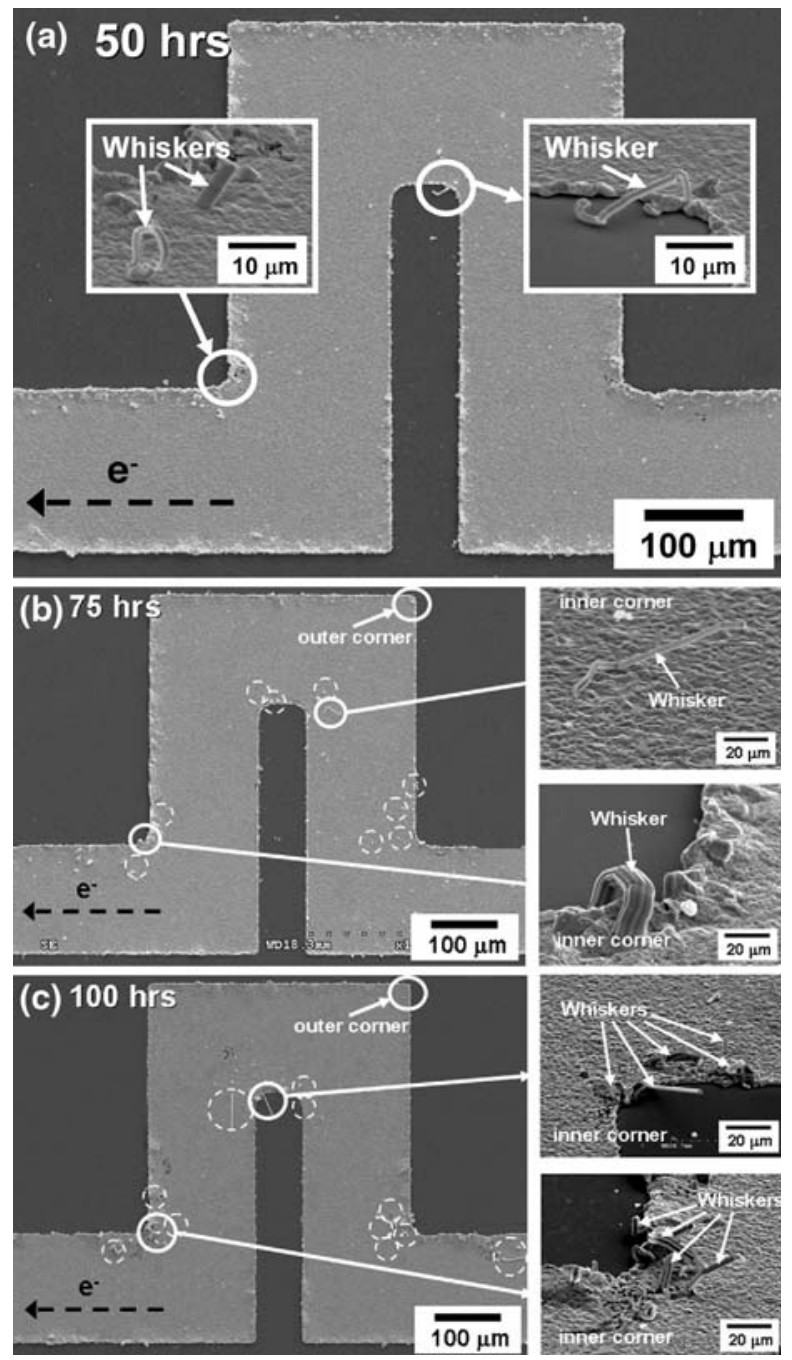

Fig. 6. SEM images at location $\mathrm{C}$ of sample set 1 after (a) $50 \mathrm{~h}$, (b) $75 \mathrm{~h}$, and (c) $100 \mathrm{~h}$ of current stress. The electric current did not pass through locations $A$ and $B$ during the current stressing.

location $\mathrm{A}$, due to its higher current density, and the formation of whiskers here was not limited to the inner corners. In contrast, even after $50 \mathrm{~h}$ of current stress, at location $\mathrm{C}$ no whisker was observed, except at the inner corners, as shown in Fig. 6a. Apparently, current crowding was able to cause the whiskers to form at a relatively low average current density, which, otherwise, would not have induced the whisker growth, even after a relatively lengthy period of current stress.

\section{SUMMARY}

The stress generated by the electromigration was able to induce the Sn whisker growth. When the current density was $3.6 \times 10^{5} \mathrm{~A} / \mathrm{cm}^{2}$, some whiskers formed in as short a time as $1 \mathrm{~h}$. Increasing the current density caused more whiskers to form and then to grow at a higher rate. When the current density was reduced to $4.5 \times 10^{4} \mathrm{~A} / \mathrm{cm}^{2}$, no whiskers 


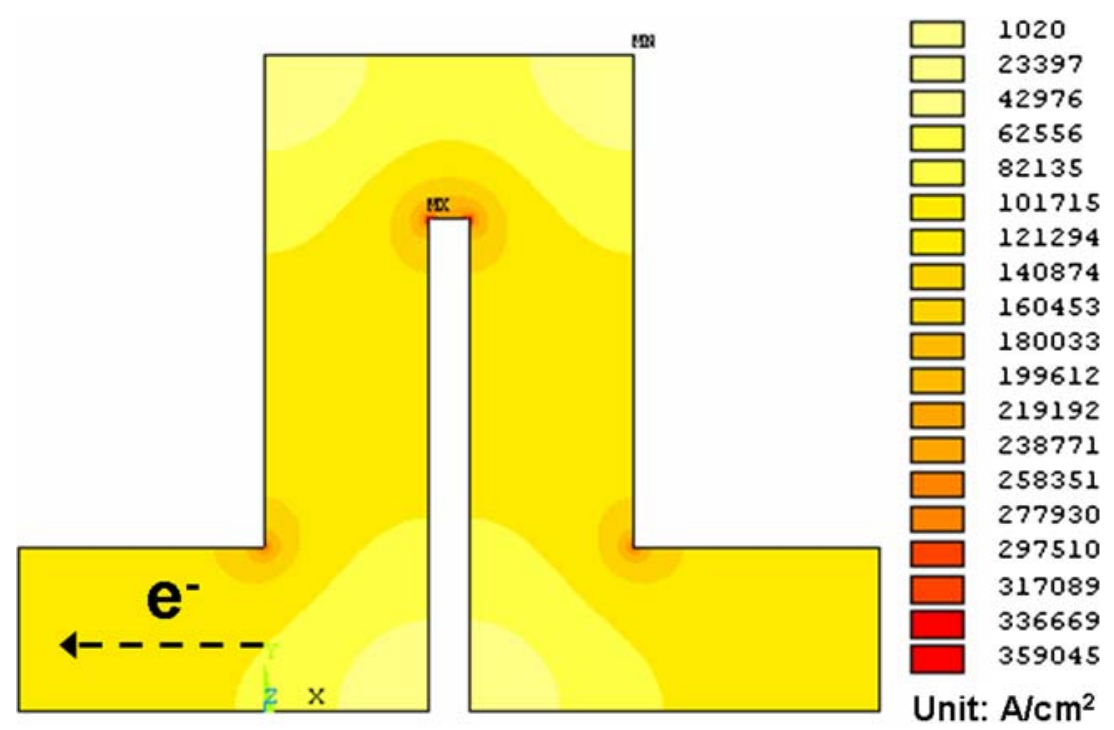

Fig. 7. Current density distribution for location $C$ of sample set 1 , simulated by the finite element method.

were observed, even after hundreds of hours of current stress. Nevertheless, with the help of the current-crowding effect, some whiskers did grow at the inner corners of the $90^{\circ}$ turn between two connecting line segments after $50 \mathrm{~h}$, when the average current density was at $9 \times 10^{4} \mathrm{~A} / \mathrm{cm}^{2}$.

Temperature played an important but complicated role with regard to the whisker formation. When the temperature was increased from $30^{\circ} \mathrm{C}$ to $50^{\circ} \mathrm{C}$, more whiskers formed, and the whiskers grew at a higher rate. When the temperature reached $70^{\circ} \mathrm{C}$, however, only hillocks formed. Thus, an optimum temperature for whisker growth existed, and this temperature was likely between $50^{\circ} \mathrm{C}$ and $70^{\circ} \mathrm{C}$.

\section{ACKNOWLEDGEMENTS}

The authors would like to thank the National Science Council of Taiwan for financial support through Grants NSC-95-2221-E-002-443-MY3 and NSC-95-2221-E-002-441.

\section{REFERENCES}

1. W.J. Choi, T.Y. Lee, K.N. Tu, N. Tamura, R.S. Celestre, A.A. MacDowell, G.T.T. Sheng, Y.Y. Bong, and L. Nguyen, 52nd Electron. Comp. \& Tech. Conf., pp. 628-633, May 28-31, San Diego, CA (2002).

2. P. Bush, G. Jones, and I. Boguslavsky, NEMI Workshop on Tin Whiskers, APEX 2003, April 1, Anaheim, CA (2003).

3. H.L. Cobb, Monthly Rev. Am. Electroplaters Soc. 33, 28 (1946).

4. S.E. Koonce and S.M. Arnold, J. Appl. Phys. 24, 365 (1954).

5. R.M. Fisher, L.S. Darken, and K.G. Carroll, Acta Metall. 2, 368 (1954).

6. W.C. Ellis, D.F. Gibbons, and R.C. Treuting, Growth and Perfection of Crystals, ed. R. H. Doremus, B. W. Roberts, and D. Turnbull (New York: Wiley, 1958), pp. 102-120.

7. U. Lindborg, Metall. Trans. A 6A, 1581 (1975).

8. K.N. Tu, Phys. Rev. B: Condens. Matter Mater. Phys. 49, 2030 (1994)

9. B.Z. Lee and D.N. Lee, Acta Metall. 46, 3701 (1998).

10. C. Xu, Y. Zhang, C. Fan, and J.A. Abys, CircuiTree 15, 94 (2002).

11. G.T.T. Sheng, C.F. Hu, W.J. Choi, K.N. Tu, Y.Y. Bong, and L. Nguyen, J. Appl. Phys. 92, 64 (2002).

12. K.N. Tu and J.C.M. Li, Mater. Sci. Eng., A 409, 131 (2005).

13. S.H. Liu, C. Chen, P.C. Liu, and T. Chou, J. Appl. Phys. 95, $7742(2004)$ 